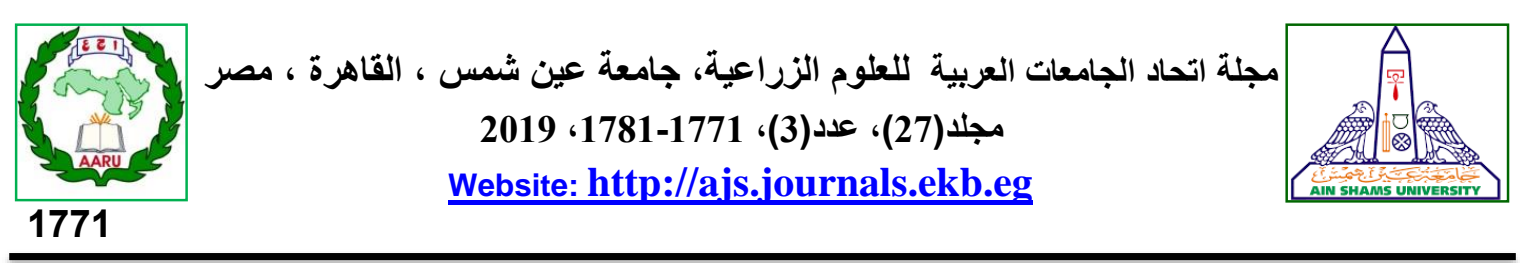

التمدد العمراني على الأراضي الزراعية في محافظة الغربية

\author{
محمد أحمد عبد السلام قنديل" - محمد بدير العراقي - محمد سيد شحاته

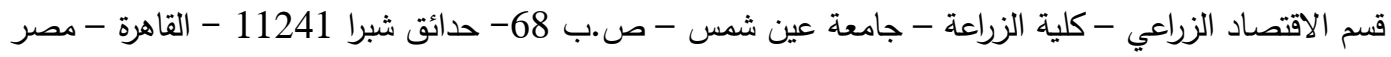

*Corresponding author: mo.kandil1978@gmail.com

Received 19 June, $2019 \quad$ Accepted 16 October, 2019

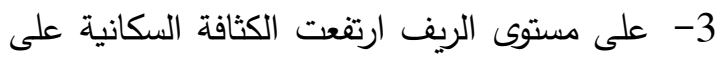

الأراضي الزراعية من حوإلى 7.3 فرد للفدان عام الفئي

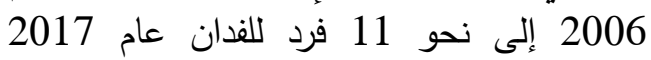

وانخفض نصيب الفرد من المساحة الزراعية من عن

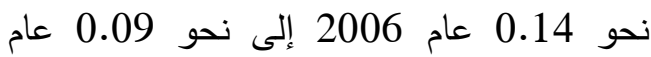

2017 و من المساحة المحصولية انخفض من 0.14

نحو 0.26 عام 2006 إلى نحو 0.09 عام

4- جاءت تقديرات معالم دالة النمو السكاني معبرة

لمدى تفاقم المشكلة و معبرة عن الزيادة المتزايدة في عدد السكان بمعدل قدر بنحو 0.024 سنوياً

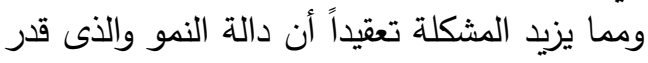

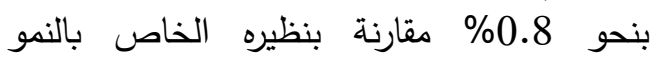
السكاني والذى قدر بنحو 0.8\% مقارنة بنة 2.4.

5- بتقدير دالة النمو في المساحة المحصولية اتضح

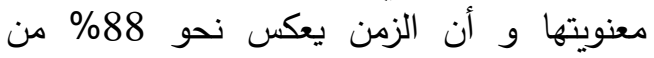

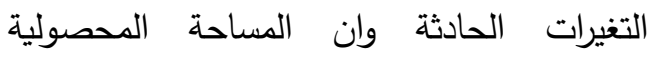

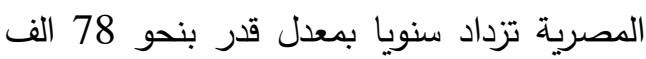
فدان وذلك على المستوى القومي.

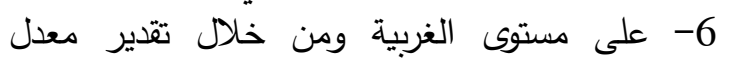

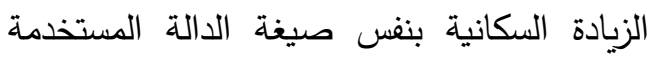

تبين أن معدل النمو السكاني في الغربية يقل قليلاً

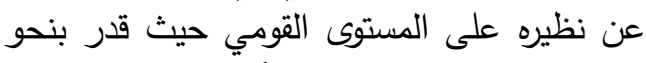
2.1\% خلال نفس الفترة. و أن معدل التغير جاء لتئ

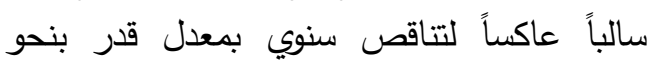

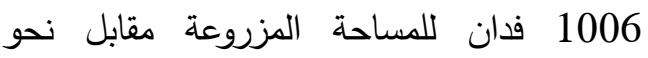
2992 فدان للمساحة المحصولية.

[142]

تعتبر الأرض هي احد اهم العوامل في توفير

الاحتياجات البشرية بصفة عامة و الغينة الغذائية بصفة

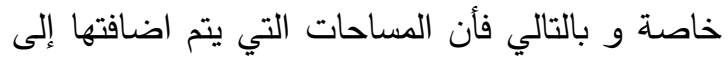

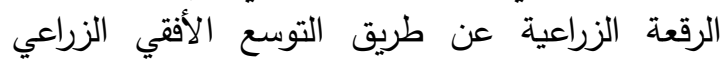

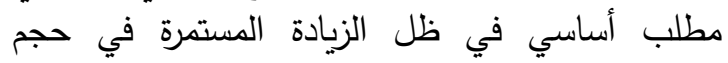

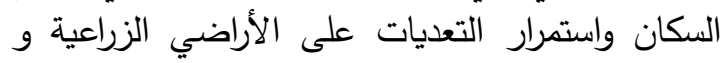

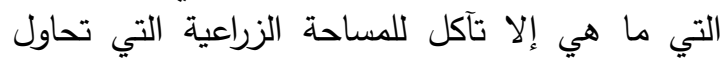

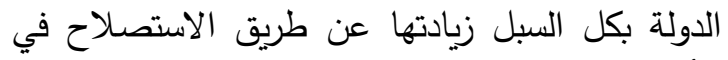
الأراضي الصحراوية وتزداد هذه المشكلة بازئ لإدياد

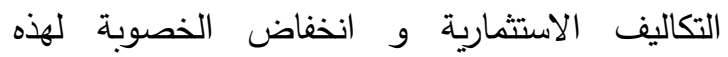
الأراضي والتي لا تعوض المستقطع في المدى القصير

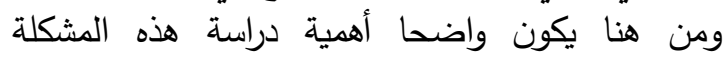

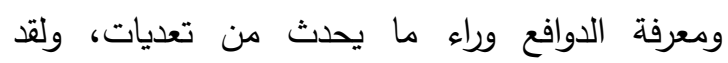
اوضحت الدراسة الهم النتائج التالية:

1- تتقسم عمليات التعدي إلى ثلاث أقسام (التبوير التهائ - التجريف - البناء) وتمثل هذه نحو (35.5\%

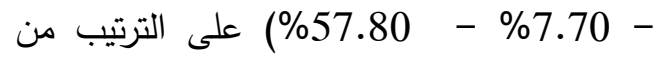
المساحة الإجمالية المتعدي عليها و التي تبلغ الترني

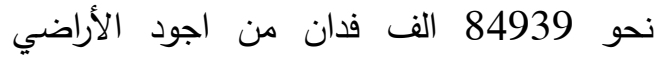
الزراعية وذلك خلال الفترة 2011/1/25م وحتى

$$
\text { • 2018/11/18 }
$$

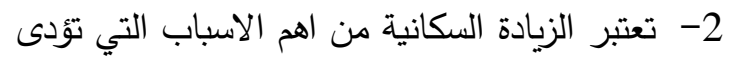

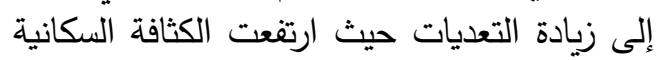

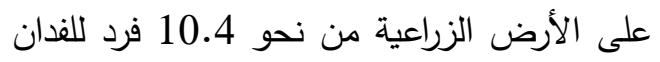
عام 2006 إلى نحو 15.4 فرد للفدان من نحو 


$$
\text { قنديل - العراقي - شحاته }
$$

تأتى في المقدمة ثم العوامل الاقتصادية والاجتماعية بل

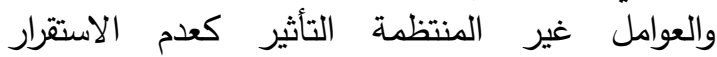

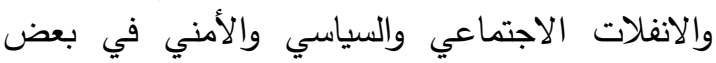
الأوقات جعلت وتسبيت في استقطاع أجزاء لا لاعيتهان الأنيان

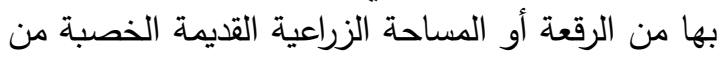

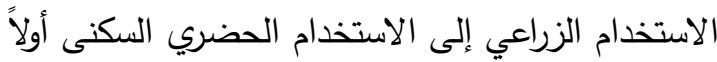

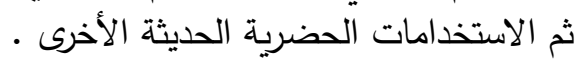

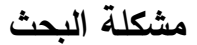

تعتبر الأرض هي أحد أهم العوامل في توفير الاحتياجات البشرية بصفة عامة والغذائية بصفة الثية خاصة وبالتالي فإن توفير هذه الاحتياجات يتوقف بصورة أساسية على حجم التطور في المساحات التئي الأرضية الزراعية ومتوسط نصيب الفرد منها حيث النيا أن محدودية

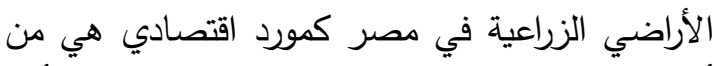
أهم التحديات التي تواجه التتمية الزراعية لتحقيق الأمن

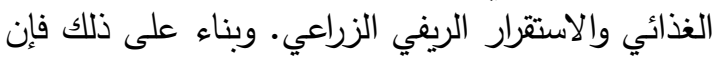

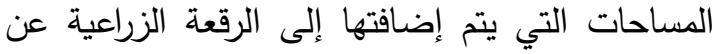

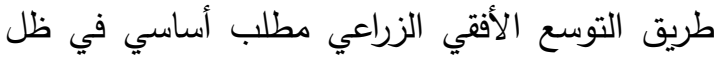

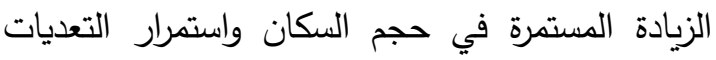
على الأراضي الزراعية.

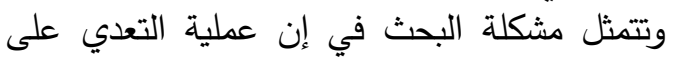

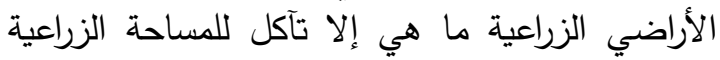

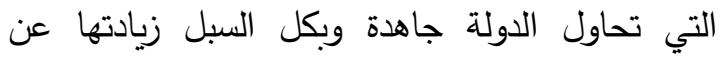

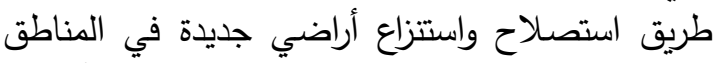

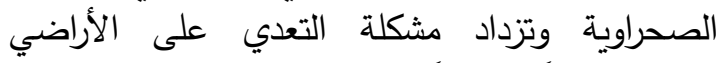

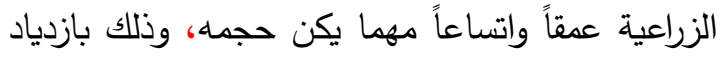

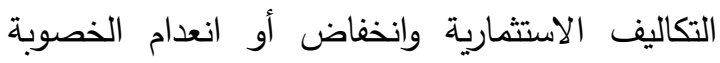

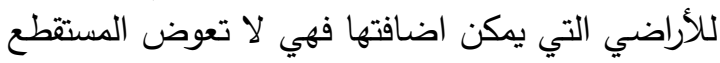

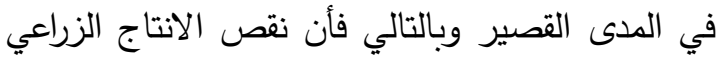

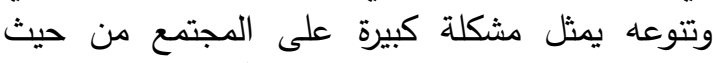
استتزاف كميات كبيرة من النقد الأجنبي لمحاولة سد

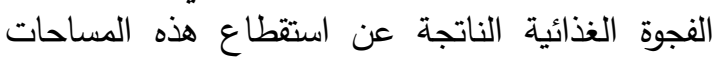

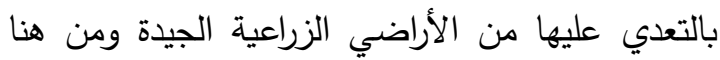

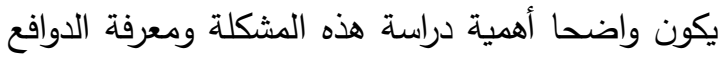

$$
\text { وراء ما يحدث من تعديات . همئة دراسة هذه }
$$

ويتضح من التقديرات السابقة ان التقديرات الاحصائية للمساحة المزروعة والمحصولية بمحافظة

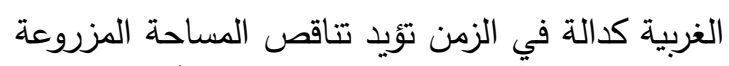

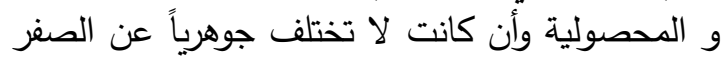
إلا أنه يفسر الثواهد المتاحة منذ عام 2011. ويمكن القول ان التعديات على الأراضي الزئل الزراعية

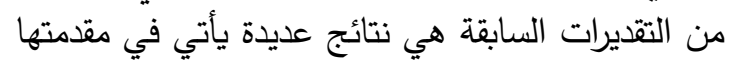

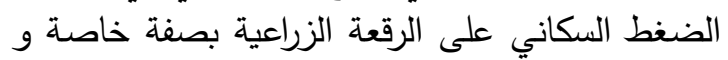

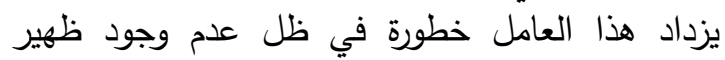
صحراوي لمحافظة الغربية.

الكلمات الدالة: الأراضي الزراعية، تجريف التربة الزراعية، التمدد العمراني في محافظة الغربية التراعية

\section{مقدمـة}

تعد الأراضي الزراعية أحد أهم الموارد الاقتصادية

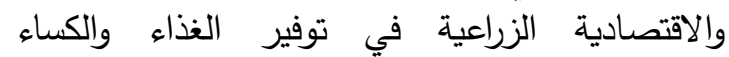

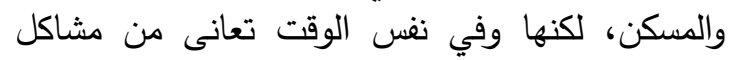

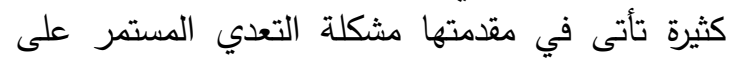

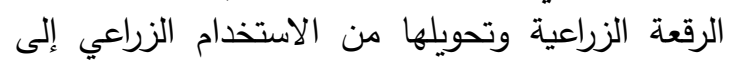

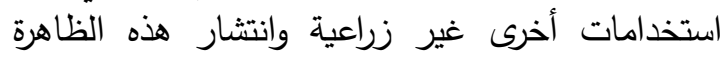

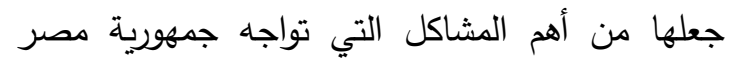

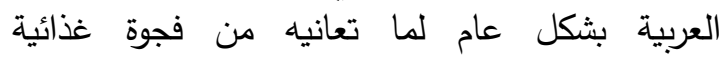

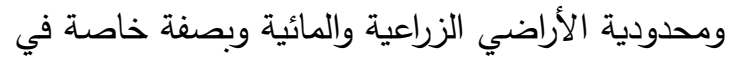

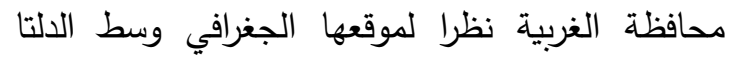

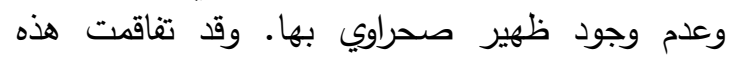
الظاهرة بشكل ينذر بالخطر بعد 25 يناير 2011 حيث ساهم الانفلات الأمني وتراجع الوضع بالفئ الاقتصادي

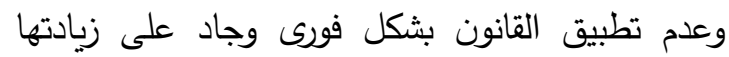

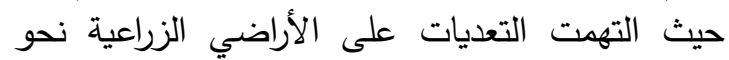

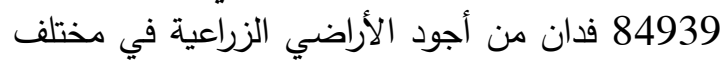

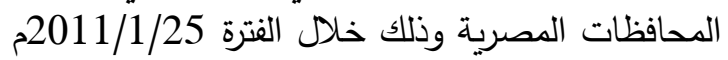

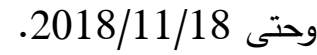

ولما كانت الموارد الأرضية الزراعية ضمن الموارد

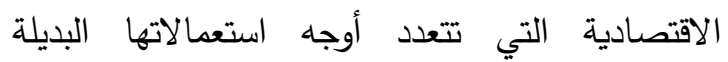

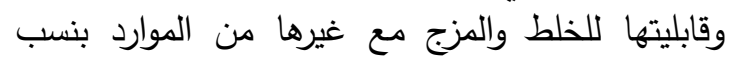

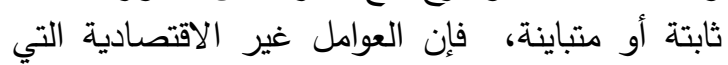


المساحة والأهمية النسبية حيث بلغت مساحة التعدي

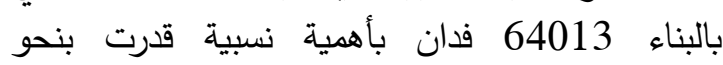
57.8 من إجمالى حجم التعدي يليه في المرتبة

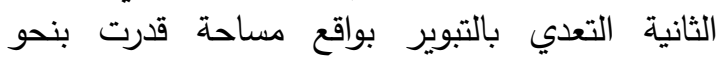

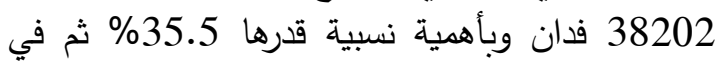

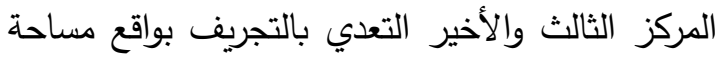
قدرت بنحو 8525 فدان وبأهمية نسبية قدرها وذلك خلال الفترة من عام 1983 وحتى عام 2010 نان

جدول 1. أشكال ومساحات التعدي على الأراضي

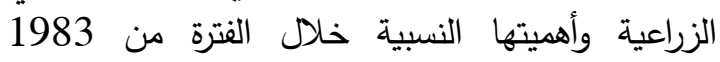
وحتى عام 2010 في جمهورية مصر العربية

\begin{tabular}{|c|c|c|}
\hline الأهمية النسبية & المساحة بالفدان & مصدر التعدي \\
\hline$\% 35.50$ & 38202 & التعدي بالتبوير \\
\hline$\% 7.70$ & 8525 & التعدي بالتجريف \\
\hline$\% 57.80$ & 64013 & التعدي بالبناء \\
\hline$\% 100$ & 110740 & الجملة \\
\hline
\end{tabular}

أهم مسببات التعدي على الأراضي الزراعية في مصر ومحافظة الغربية لهذا كان من الضروري البحث والتقصي عن التصني مسببات التعدي على الأراضي الزراعية وما تلتضدي ولئهن من عوامل ومؤثرات وإيجاد واظظهار أهمها ودراستها

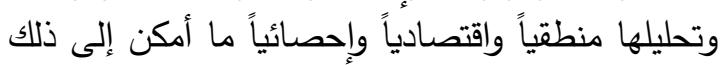

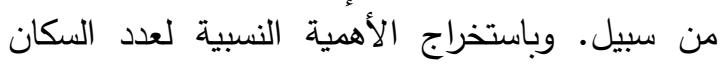

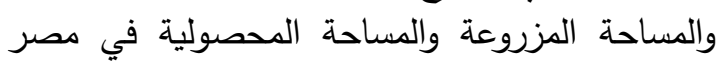
أي على المستوى القومي وعلى مستوى محافظة الغربية

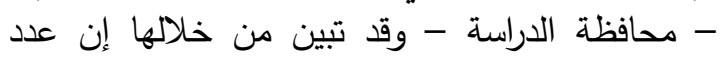
السكان الإجمالي قد زاد وباستمرار تدريجيا من مستواه

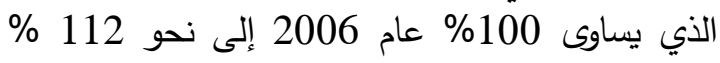
عام 2011 ليصل إلى نحو 132 \% ع في عام 2017 في ندام 2006 وذلك من مستواه عام 2006. أما المساحة المزروعة عام المعام

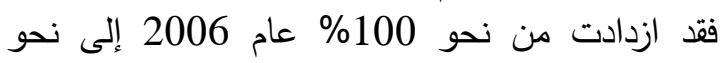
103\% عام 2011 لتصل في عام 2017 إلى نحو إلى 109\%. وارتغعت المساحة المحصولية من نحو نحو

\section{هدف البحث}

يهدف البحث إلى التعرف على الاثار الاقتصادية

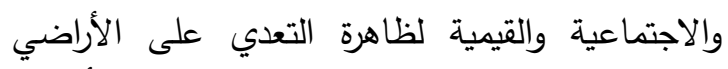

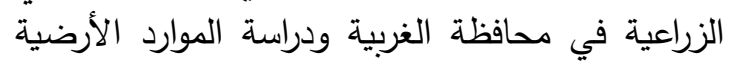

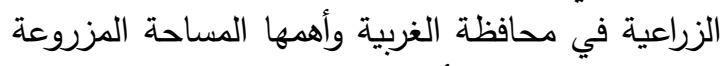

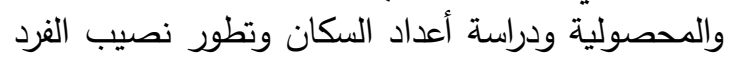

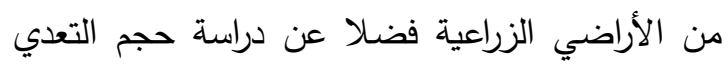

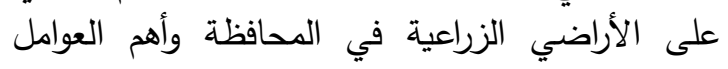
المؤدية إليه ثم وضع تصور لبعض النع الحلول التي يمكن

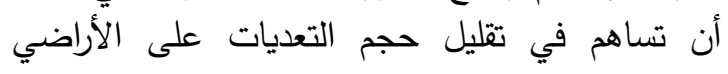
الزراعية بالمحافظة في فئل

$$
\text { أشكال التعدي على الأراضي الزراعية }
$$
1-التعدي بالتبوير

حيث يلجأ بعض المزارير التين إلى ترك الأرض بدون

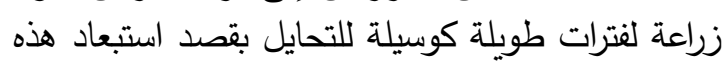

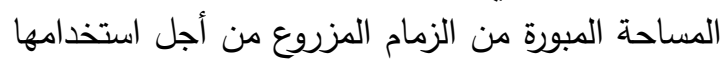

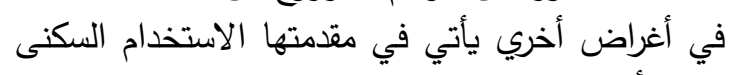
لنفسه أو لغيره عن طريق بيعها.

2- التعدي بالتجريف

وهذا التعدي يترتب عليه إضجريف إضعاف للطبقة السطحية

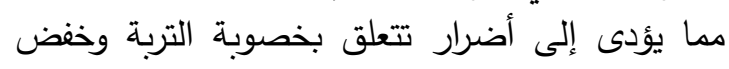

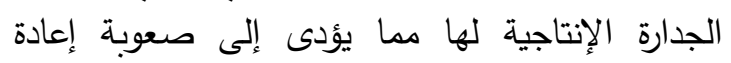
استخدامها. - ارة الإنتان 3-التعدي بالبناء وهى من أخطر أنواع المشاكل التي تواجه الزراعة

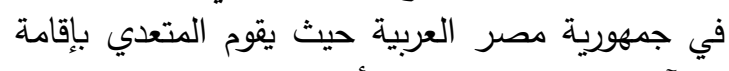

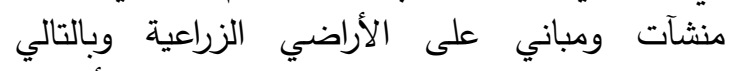
تستقطع هذه المساحة المتعدي عليها من الأني أراضي لزئي الإنتاج الزراعي وقد يقدم ببيعها للغير بعد تقسيمها إذاً

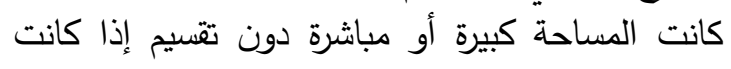
المساحة صغيرة . المبات كبيرة ويتضح من الجدول رقم (1) والذي يبين مساحات وأثكال التعدي على الأراضي الزراعية أن الندي المساحة

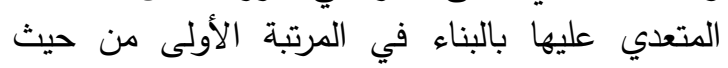




$$
\text { قنديل - العراقي - شحاته }
$$

المزروعة بالمحافظة مما يشير إلى حدوث التعديات على المساحة المزروعة وأن المزارعين يحاولون معالجة المعاد ذلك قدر الإمكان بزيادة المساحة المحصولية بزيادية

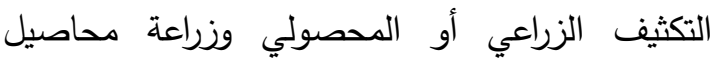
وزروع تتخف مدة مكوثها في الأرض .

الكثافة السكانية والنسب السكانية الأرضية بمصر وبمحافظة الغربية يعد تعداد السكان الإجمالي معيارا دقيقا لمدى أهمية

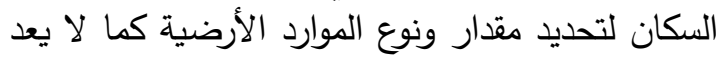

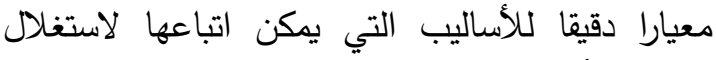
الموارد الأرضية خاصة الزراعية منها وللكثافة السكانية لإنالية

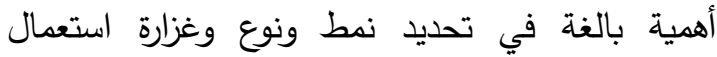

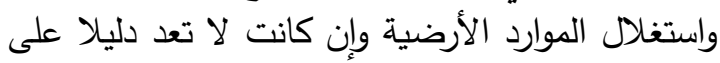

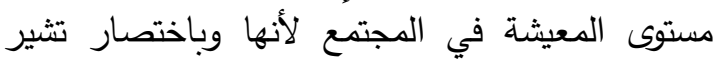
إلى عدد السكان على الكيلو متر المربع أو على الهي الفئه الفدان

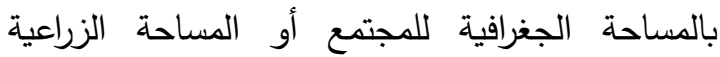

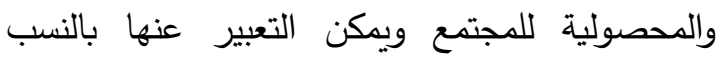
السكانية - الأرضية الزراعية أو حمولة الفدان الزراعي لأنيان

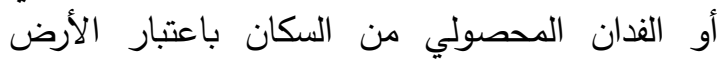

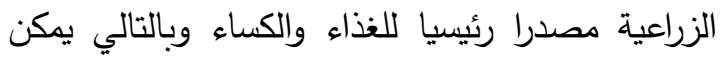

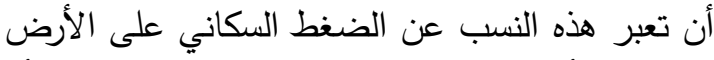

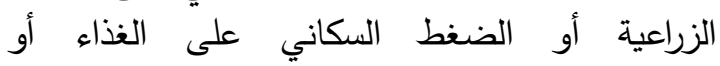
الاحتياجات الغذائية . الزفية

وتختلف العلاقة بين قدرة الموارد الأرضية الزراعية

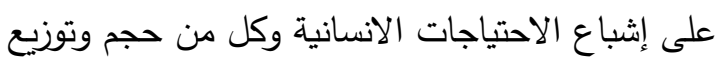

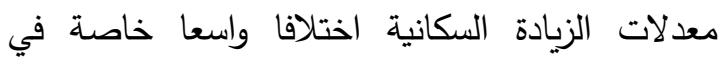
المجتمع التقليدي غير المتقدم حيث الثيادة الثبات النسبي

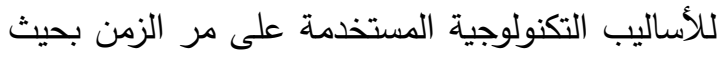

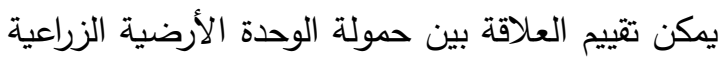

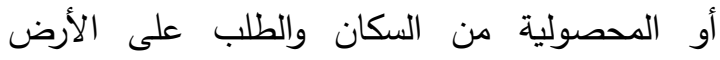

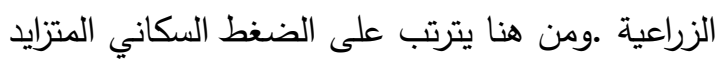

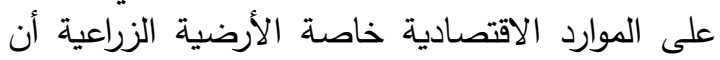

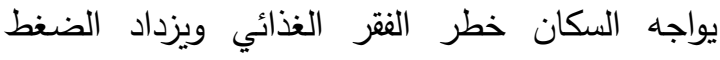

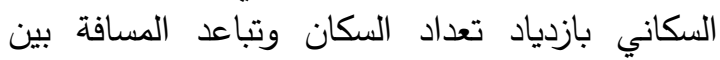
الاحتياجات البشرية من السلع الغذائية والكميات

المنتجة منها.
100\% عام 2006 إلى نحو 103\% عام 2011

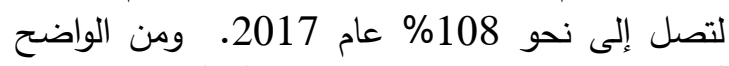
أن الزيادة السكانية تربو عن ضعف أو أو أضعاف الزيادة

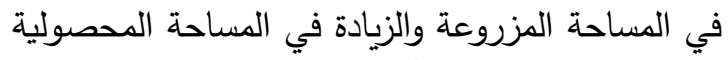

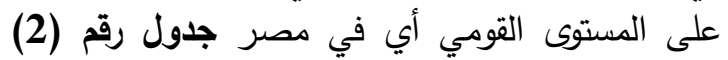

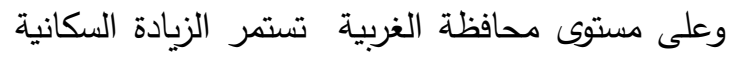

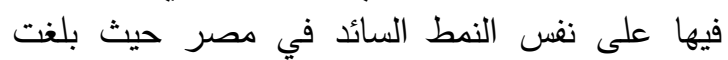

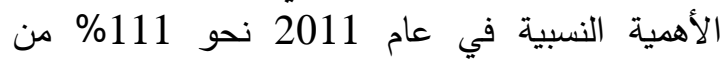
مستواها عام 2006 لتصل إلى نحو 125\% من فن العام مستواها في نفس العام وفي ريف محافظة الغربية تعرضت الأهمية النسبية لعدد السكان الريفية بالازدياد

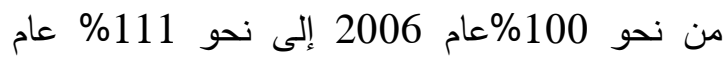

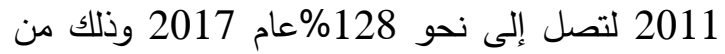
المستوى السائد عام 2006 وهنا تجدر الاشارة إلى أن

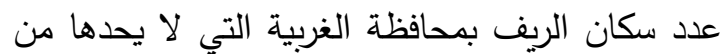

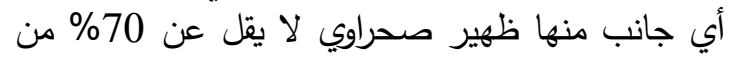

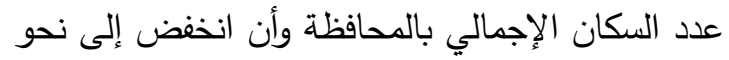
69 من عدد السكان الإجمالي عام 2014 ليرتفع الإلى الفيكان إلى نحو 72\% من العدد الإجمالي للسكان عام 2017

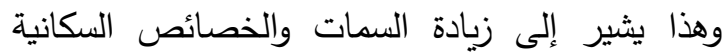
الريفية بمحافظة الغربية جدول رقم (2). ولقد تبين من خلال استخراج الأهمية للمساحة

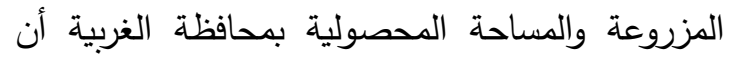

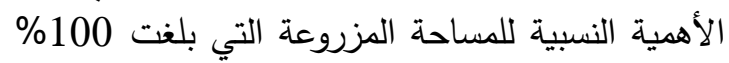
عام 2006 قد انخفضت إلى نحو لتنخفض أكثر في عام 2017 حيث وصلت إلى نح نحو

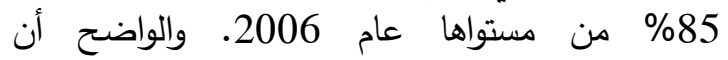
الانخفاض كان أكثر نسبيا فيما بعد أو من عام 2011

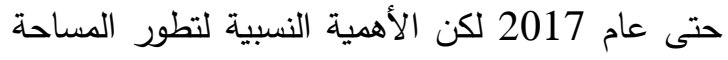
المحصولية بمحافظة الغربية كانت تدور حول مستواها عام 2006 فازدادت عن ذلك المستوى حتى وصلت

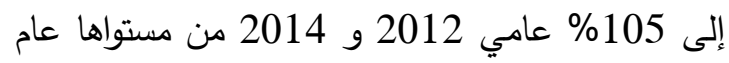

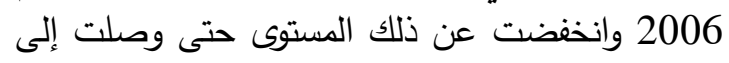
أدناها عام 2017 حيث بلغت 97 ون ون دن دن مستواها عام 2006. ومن ذلك يتضح مدى النقص في المساحة 


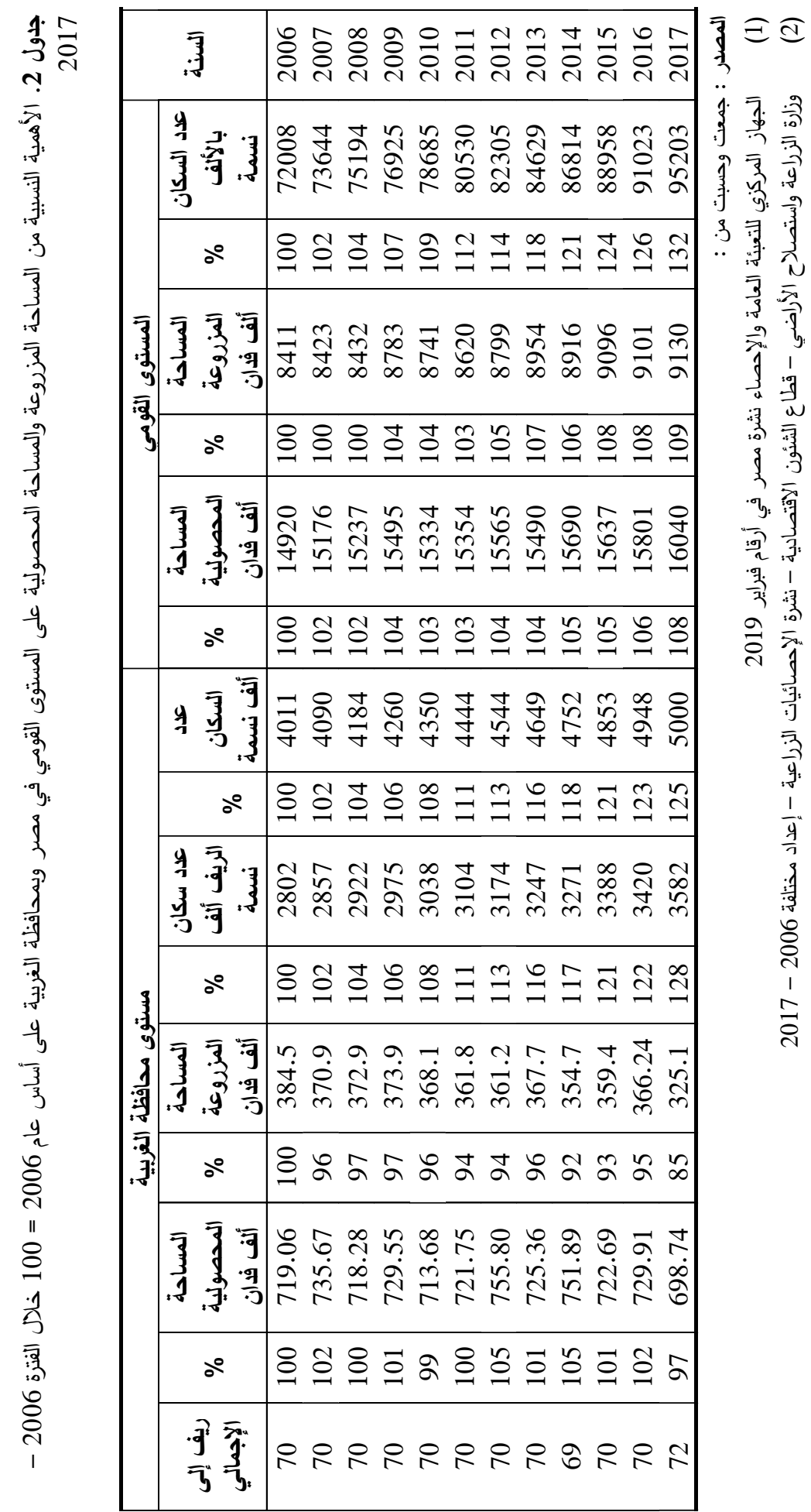




$$
\text { قنديل - العراقي - شحاته }
$$

من المساحة المحصولية من نحو 0.18 فدان عام 2006 إلى نحو 0.14 فدان عام 2017 وإذا ما أخدان عان أخدام

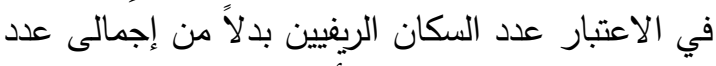

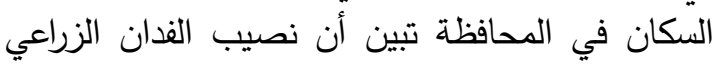

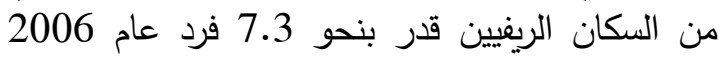

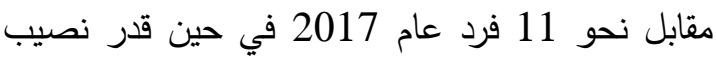
الفدان المحصولي من السكان الريفيين بنحو 306 فين فرد فرد 2017 فرد

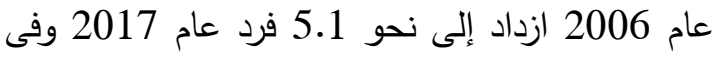
نفس الوقت انخفض نصيب الفرد فيه بمحافظة الغربية

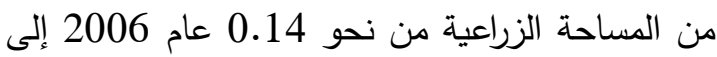

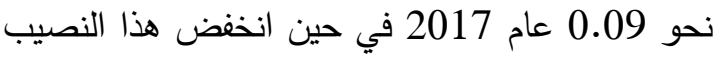
من المساحة المحصولية من نحو 0.26 نام 0.20 عام 2006

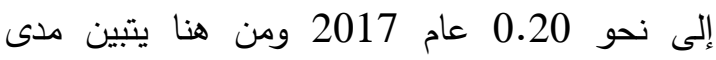
خطورة وصعوبة ازدياد السكان خاصة

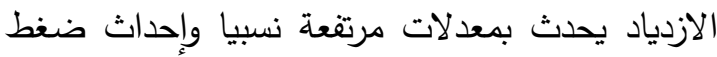

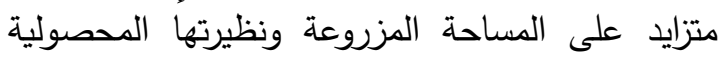

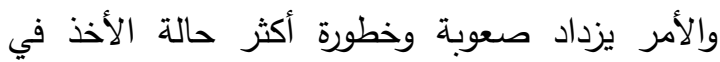

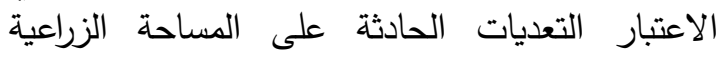
والمحصولية بالتالي بمحافظة الغربية .

تضخم مشكلة النمو السكاني وعلاقته بالمساحة الزراعية والمحصولية تيكلة

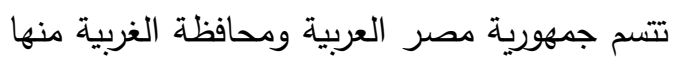
بارتفاع الكثافة السكانية على المساحة الأرضية

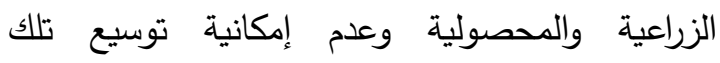

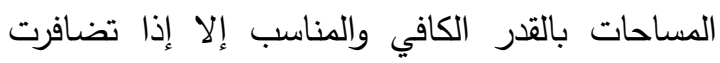
الجهود الفردية والجماعية للسكان بصفة الزبة عامة والريفيين والزراعيين منهم بصفة خاصة في تقليل أو منع التعدي الزئي

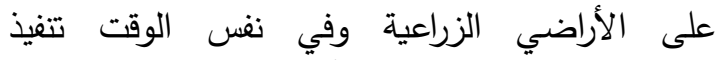
مشروعات توسيعية زراعية لأراضي جديدة ولزية وما يتطلبه

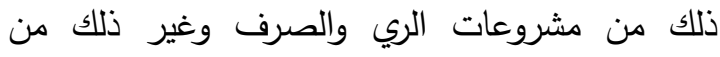
المشروعات وعلى أساس بيانات جدول (1) تمعالت استخراج

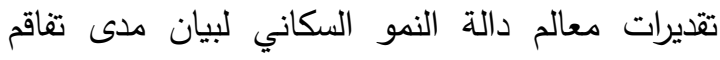

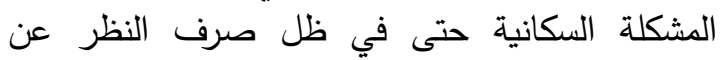

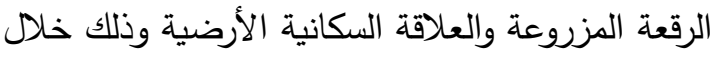

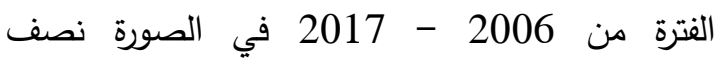

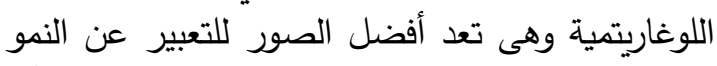
السكاني في مصر وفي محافظـة الغربيـة حيث تبين أن أن
ومن خلال استعراض النتائج المحسوبة بجدول (3)

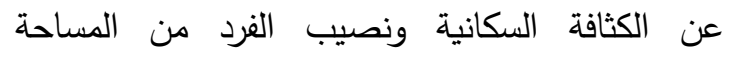
المزروعة والمحصولية في مصر وفي محافظة الغربية

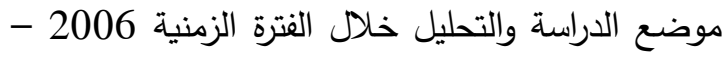
2017 ، فعلى المستوى القومي تباينت الكثافة السكانية للوحدة الأرضية الزراعية (الفدان الزراعي ) بين حدين الزين

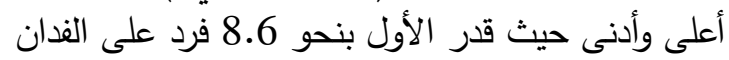

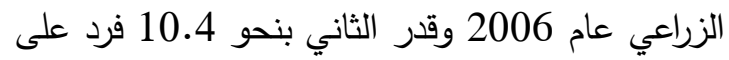
الفدان الزراعي عام 2007 في حين تباينت تلك الكثافة

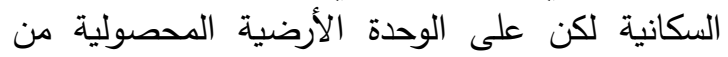
نحو 4.8 فرد للفدان المحصولي كحد أدنى عام 5.9

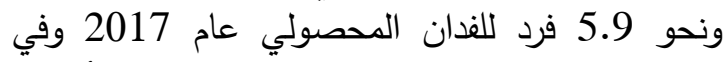
الحالتين تبين مدى ازدياد حمولة الوحدة الأرضية

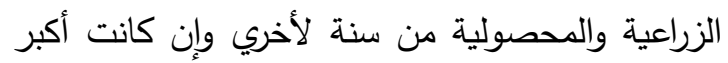
على الوحدة الأرضية الزراعية حيث أن الفدان الواحد

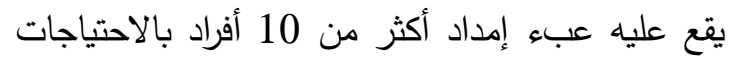

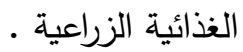

أما حالة احتساب نصيب الزئة الفرد الواحد من السكان من المساحة الزراعية ونظيرتها المحصولية يتضح أن أن الن النيان نصيب الفرد من السكان لا يزيد عين 0.12 من الفدان الزراعي ولا يزيد عن 0.21 من الفدان المحصولي لئي عام 2006 في حين ينخفض نصيب الفرد في مصر إلى نلى 096

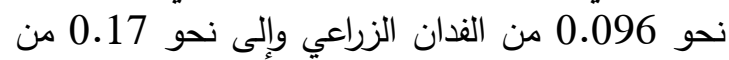

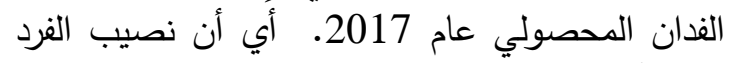

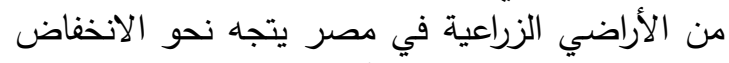

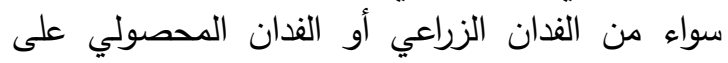

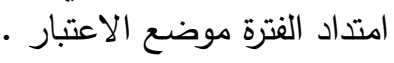

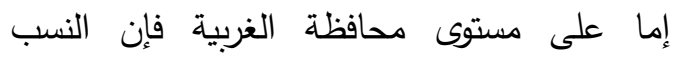
السكانية الأرضية العاكسة للكثافة السكانية والضغط لإنطان السكاني تأخذ نفس الاتجاه العام لازدياد حمولة الوحدة الأرضية الزراعية والمحصولية وأن كبر حجمها بدرجة لأنداه

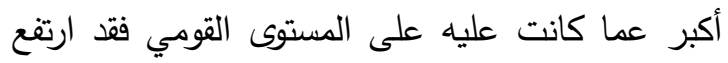

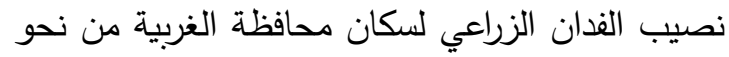

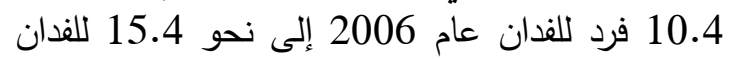
عام 2017 وذلك مقابل نحو 10.6 فرد 5.6 فرد للفذان المحصولي عام 2006 ونحو 7.2 فرد 2017 ولفيل للفدان المحصولي عام 2017 وقد انخفض نصيب الفرد من فن فئ

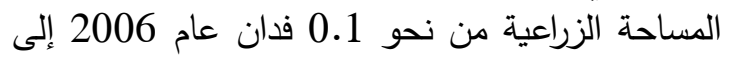
نحو 0.07 فدان عام 2017 كما انخفض نصئ نصام نصام الفرد 


\begin{tabular}{|c|c|c|c|}
\hline \multicolumn{2}{|c|}{$\overline{7}$} & & 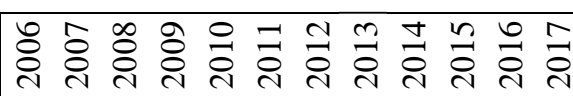 \\
\hline \multirow{4}{*}{ 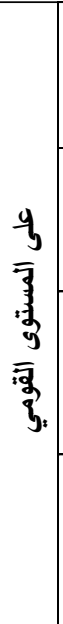 } & $\begin{array}{l}\frac{9}{2} \\
\overline{7} \\
\frac{3}{5}\end{array}$ & 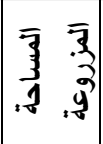 & 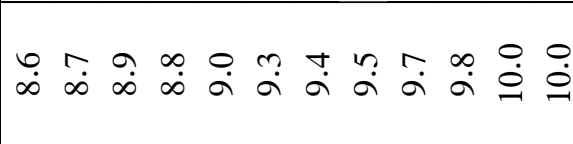 \\
\hline & 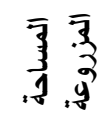 & $\overline{\overline{3}}$ & 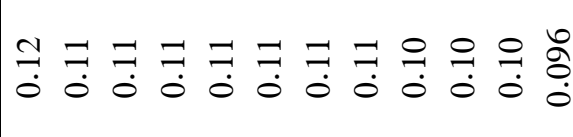 \\
\hline & $\begin{array}{l}\frac{9}{7} \\
\overline{3} \\
\frac{3}{3}\end{array}$ & 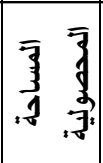 & 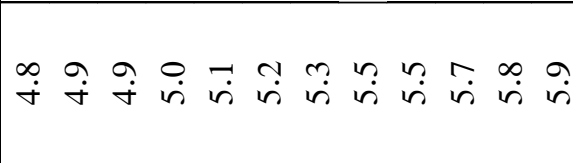 \\
\hline & 牙蛹 & $\begin{array}{l}\frac{9}{7} \\
\overline{3} \\
\frac{3}{3}\end{array}$ & 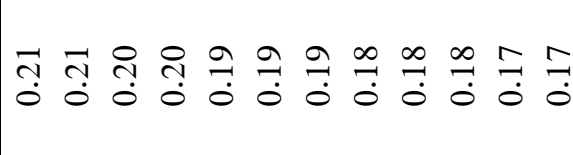 \\
\hline \multirow{8}{*}{ 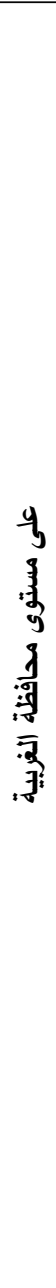 } & $\begin{array}{l}9 \\
\frac{9}{7} \\
\overline{3} \\
\frac{1}{3}\end{array}$ & 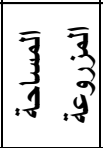 & 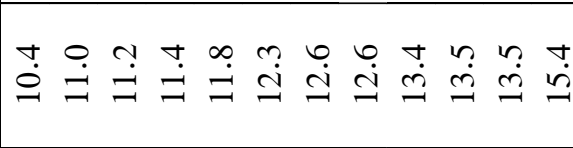 \\
\hline & 牙高 & $\begin{array}{l}\frac{9}{9} \\
7 \\
\overline{3} \\
\frac{3}{2}\end{array}$ & 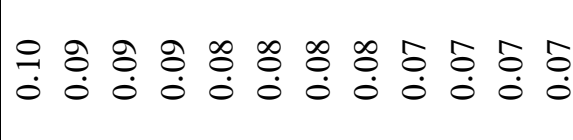 \\
\hline & $\begin{array}{l}\frac{9}{7} \\
\overline{3} \\
\frac{3}{7}\end{array}$ & 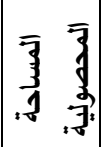 & 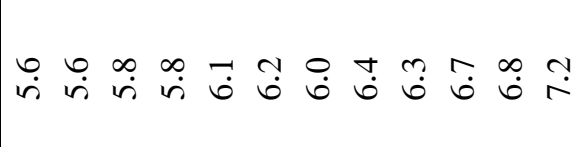 \\
\hline & 牙戠 & $\begin{array}{l}\frac{9}{7} \\
\overline{3} \\
\frac{3}{7}\end{array}$ & 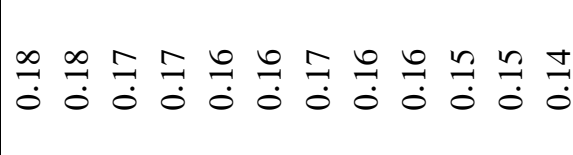 \\
\hline & 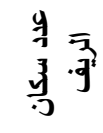 & $\left|\begin{array}{cc}\overline{3} & \overline{3} \\
3 & 3 \\
.4 & 9 \\
.9\end{array}\right|$ & 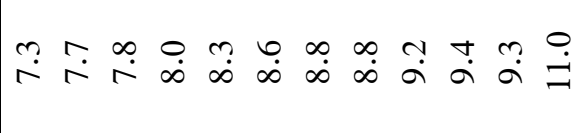 \\
\hline & 牙亨 & $\begin{array}{l}3 \\
\frac{3}{2} \\
\overline{3} \\
.9\end{array}$ & 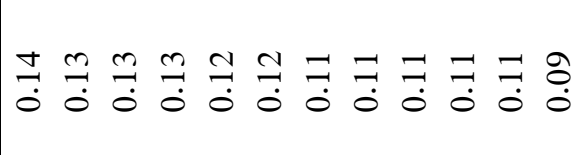 \\
\hline & $\begin{array}{l}y \\
y \\
y \\
y \\
y\end{array}$ & 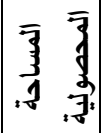 & 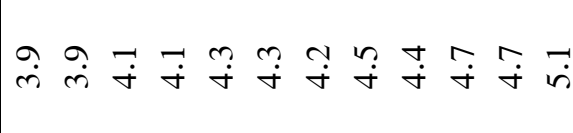 \\
\hline & 牙事 & 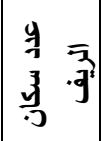 & 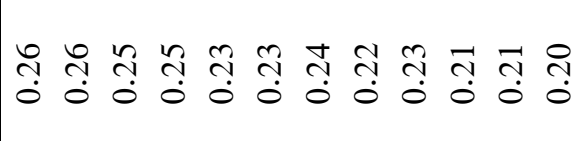 \\
\hline
\end{tabular}


ومن التقديرات يتضح معنويتها وأن الزمن يعكس نحو

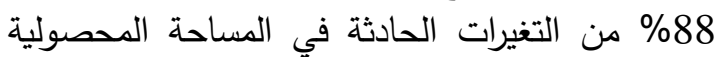

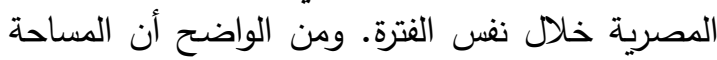

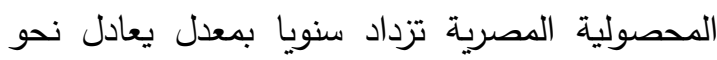
78 ألف فدان وهذه الزيادة في مواجهة الزيادة السكانية

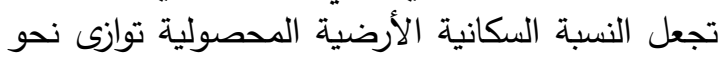

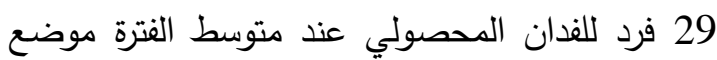

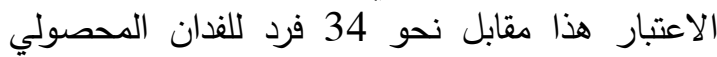

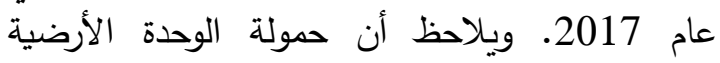

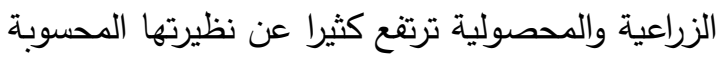

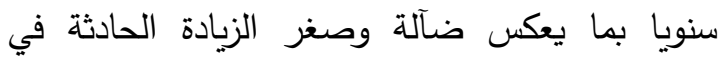
المساحة الزراعية ونظيرتها المحصولية إذا ما قورنت

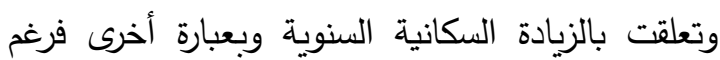

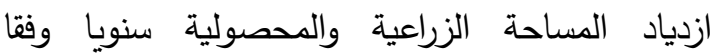
للتقديرات المتحصل عليها فإن معظم الثواهد والدلائل

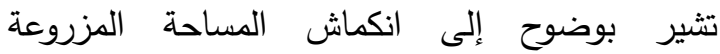
والمحصولية خاصة بالأراضي الزراعية القديمة حيث النياشي

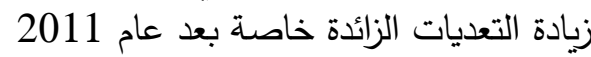
أما في محافظة الغربية فالأمر لا يختلف كثيرة التياً عما هو

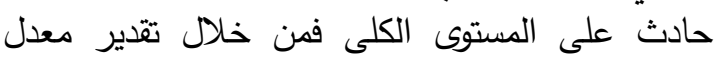
الزيادة السكانية بنفس الصيغة الدالة المستخدمة سلفا يتبين أن:

$\ln \mathbf{Y}^{\wedge} \mathbf{i}=15.178+0.021 X \mathbf{X}$

$\mathrm{T}_{\mathrm{C}}=(\mathbf{6 0 5 3 . 4 3 2 )}(\mathbf{6 1 . 1 7})$

$R^{2}=0.997 \quad F_{C}=3741.742$

ومن الواضح ان معدل النمو السكاني بمحافظة

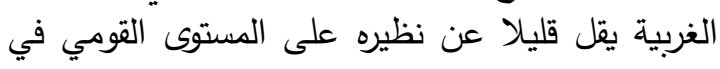
مصر فقد قدر بنحو 2.1\% خلال الفترة 2006 -

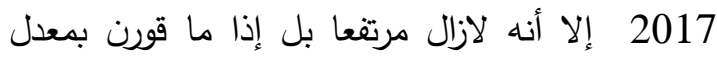

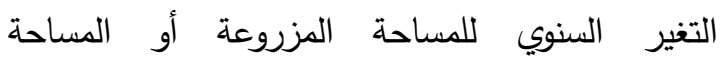

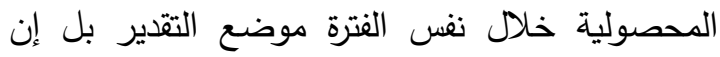

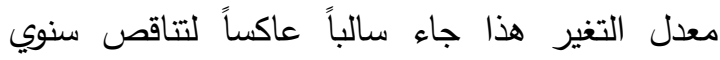

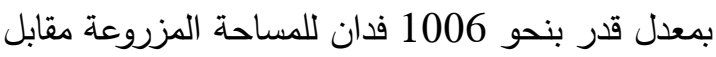

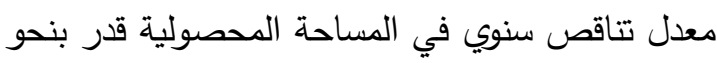

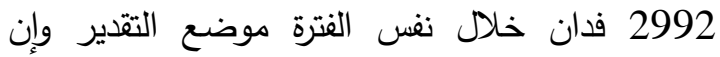
كانت معدلات التتاقص هذه غير معنوية من الوجهة

\section{$\operatorname{Ln} Y_{i}=11.153+0.024 X_{i}$}

(2781.757) (44.922)

$\mathrm{R}^{2}=0.995$

$F_{C}=2017.961$

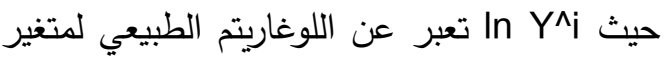

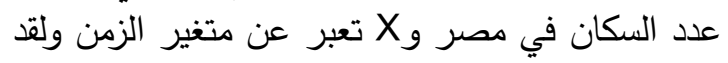

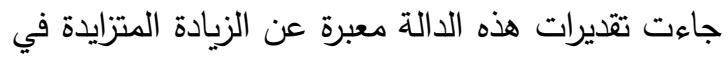

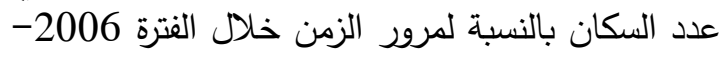

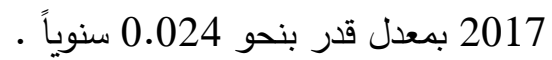
ومما يزيد المشكلة قيد الدراسة تعقيداً وخطورة أن الن النقاً دالة النمو في الرقعة المصرية الإجمالية المزروعة المالدة جاءت دالة خطية مستقيمة ذات معدل ثابت للزيادة الإناية

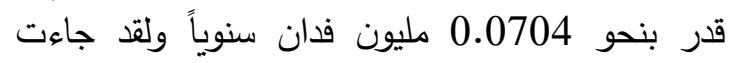
نتائج هذه الدالة على النحو التالي :

\section{$Y^{\wedge} \mathrm{I}=8.326+0.0704 X i$}

$T_{C}=(154.185)$ (9.591)

$\mathrm{R}^{2}=0.902$

$F_{C}=92.041$

حيث Y^i تعبر عن المساحة المزروعة بالمليون

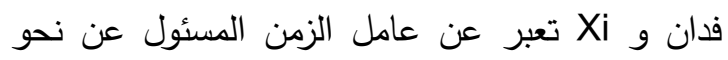

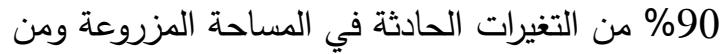
ذلك يتضح مدى ضآلة معدل نمو المساحة المزروعة المدات

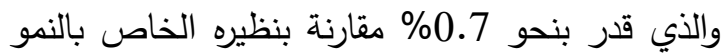

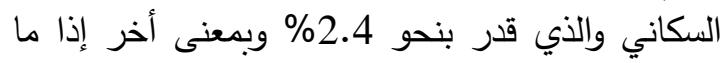
اقتصرت اعالة الزيادة السكانية السنوية على الإنى الازدياد

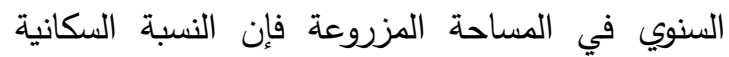
الأرضية بلغت نحو 38 فرد للفدان عند الزيادة السكانية عام 2017 وبلغت هذه النسبة نحو 33 فرد للفدان

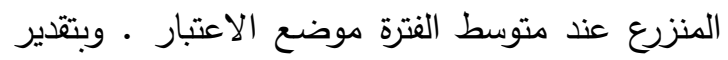
دالة النمو في المساحة المحصولية القومية أو في التئي مصر فقد جاءت التقديرات على النمو التالي : لمباحة التحمية

\section{$Y^{\wedge} i=14.969+0.078 X i$ \\ $T_{C}=(232.869) \quad(8.620)$}

$\mathrm{R}^{2}=0.881 \quad \mathrm{~F}_{\mathrm{C}}=74.310$

حيث ب̂ تمثل المساحة المحصولية المصرية خلال الفترة موضع الاعتبار Xi تمثل عامل الزمن 
هذه تتأكد المعنوية الإحصائية لمعدل النمو السكاني

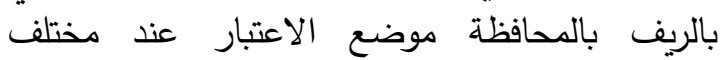
مستويات المعنوية وأن هذا المعدل يدنو كثيراً من نظيره

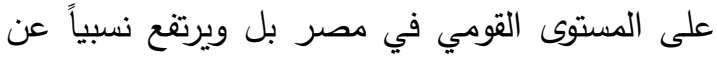
نظيره المقدر لإجمالي عدد السكان بالمحافظة موضع فئع

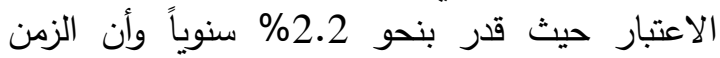
يشرح نحو 99\% من التغيرات التي تعرض لهار سكان ريف محافظة الغربية .

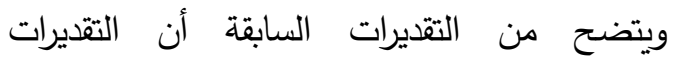

الإحصائية للمساحة المزروعة والمحصولية بمحافظة

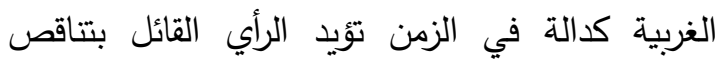

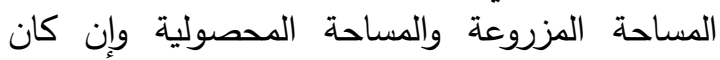
بمعدلات لا تختلف جوهرياً عن الصفر إلا أنها النه يفسر

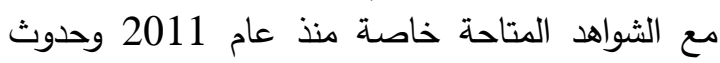
انفلات أمني واجتماعي وحدوث تغيرات المنات ثقافية وقيمية

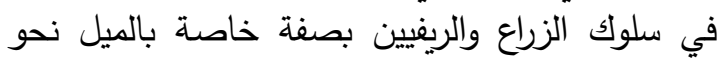

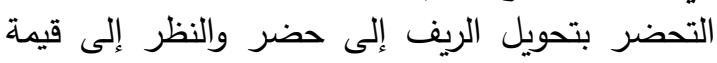

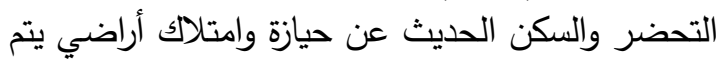

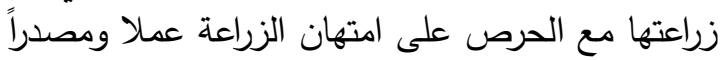

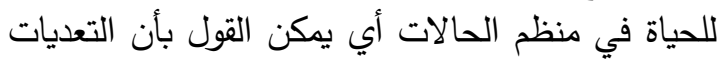

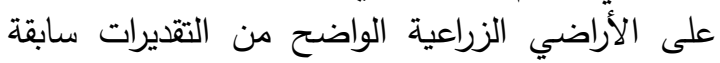

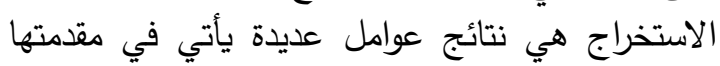

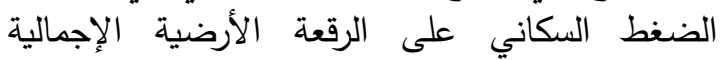

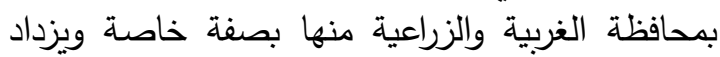

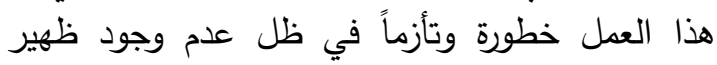

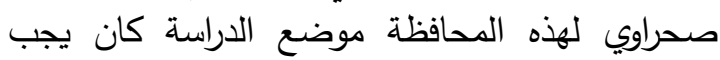
توفيره من قبل . والعامل التالي للضغط التيل السكاني يتمثل في تغيرات

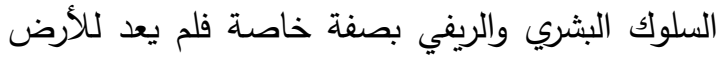
الزراعية وامتلاكها نفس القيمة القية السلوكية الاخلاقية القديمة بل سادت عليها قيم التحضر والاعتماد على التى الدولة في توفير كافة أو معظم الاحتياجات الغذاعئية

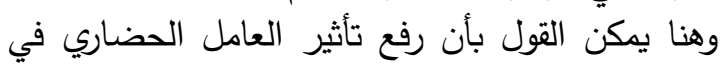

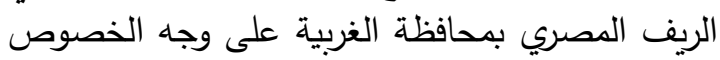

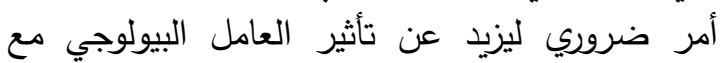

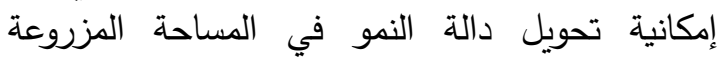

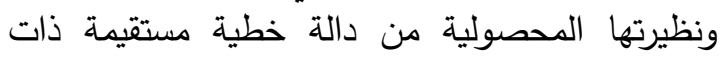
معدل تغير ثابت سنويا إلى دالة غير خطية دالة خطية ذات معدل

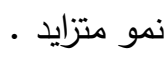

الاحصائية بما يمكن أن يثير إحصائيا أيضا وليس

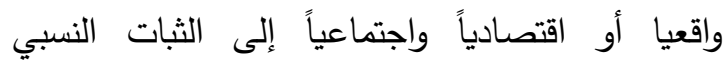
للمساحة المزروعة والمساحة المحصولية بمحافظة المانية

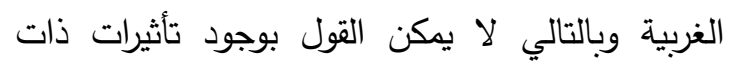
أهمية يعكسها عامل الزمن إلا في نطاق النالي النمو السكاني

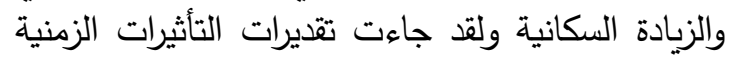

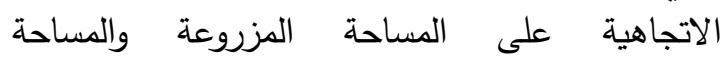
المحصولية على النحو التالي:

$Y^{\wedge} i_{1}=387.074-1.006 \mathrm{Xi}$

$T_{C}=(9.899) \quad(-0.183)$

$R^{2}=0.004$

$Y^{\wedge} i_{2}=752.313-2.992 X i$

$\mathrm{R}^{2}=0.202$

(54.390) (-1.592)

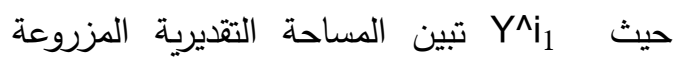
بمحافظة الغربية خلال الفترة الموضحة المساحة التقديرية المحصولية بمحافظة الغربية خلال

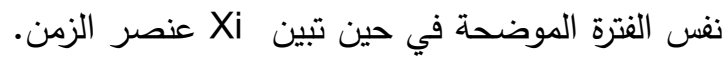

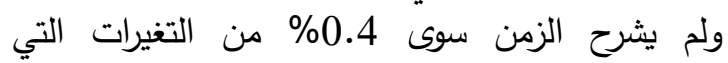
تعرضت لها المساحة المزروعة إلا أنه شرح نحو

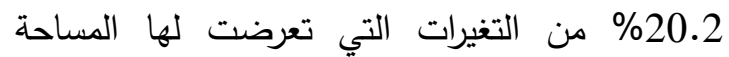

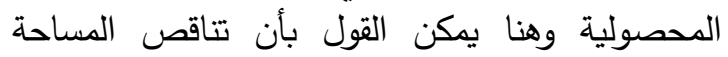

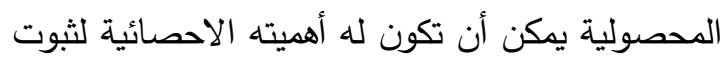

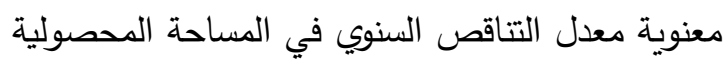

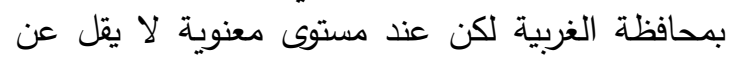

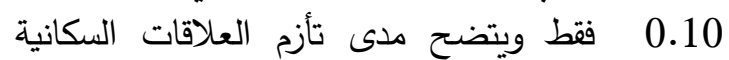

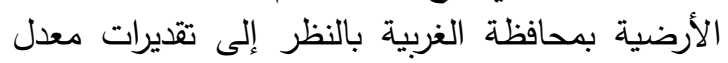

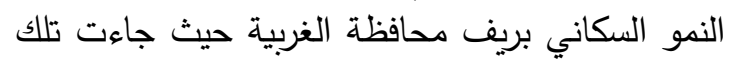
التقديرات على النحو التالي :

\section{In $Y^{\wedge} i=14.815+0.022 X i$} (3212.28) (34.371)

$\mathrm{R}^{2}=0.992$

حيث التمثل اللوغاريتم الطبيعي لعدد سكان In Y^

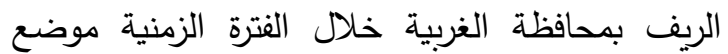
الاعتبار في حين تمثل xi عامل الزمن ومن التقديرات 


$$
\text { قنديل - العراقي - شحاته }
$$

\section{المراجـع}

التوصيـات

1) تثديد عقوبة التعدي على الأراضي الزراعية الإدارة المركزية لحماية الأراضي، 2016. التعديات

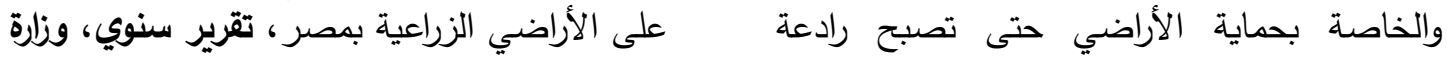

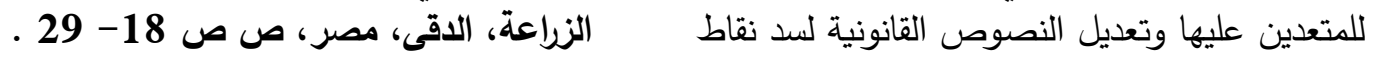

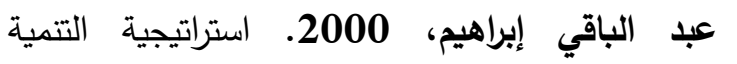
الحضريةّ في المدن المبية المصرية، مركز الدراسات

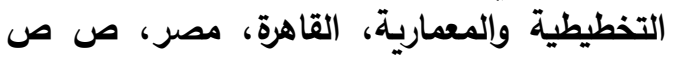

$$
\text { . } 89-82
$$

عبد العظيم أحمد عبد العظيم، 2014. الأبعاد الجغرافية لمشكلة الزحف العمراني على الزئل الأرض الأبعاد

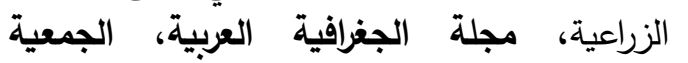

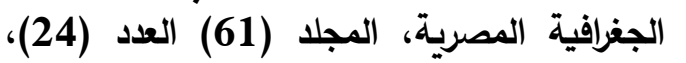

$$
\text { . } 18 \text { - } 13
$$

علي عبد المحسن، 2012.

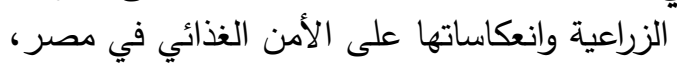

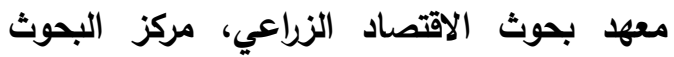

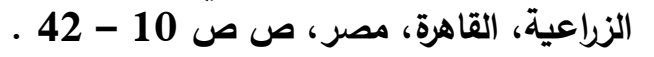

2) توعية السكان بالمجتمع و خاصة السكان الريفيين بالتداعيات السلبية للزيادة السكانية . 3) عمل ظهير صحراوي خاص بمحافظة الغربية لتلبية احتياجات التوسعات المجتمعية. 4) مراجعة قوانين البناء و التتظيم و التخطيط داجية التهل

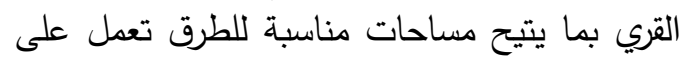
زيادة التوسع الرأسي في المباني السكنية .

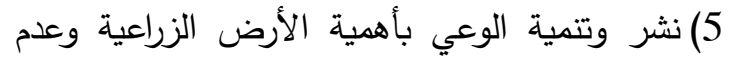

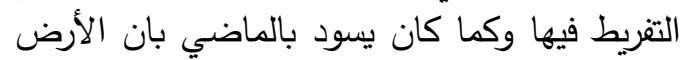
كالعرض. - كان 6) ضرورة نشر الوعي بأهمية الريف والزراعة للحضر في توفير الغذاء وامتصاص فير القوي العاملة وخاصة الرية

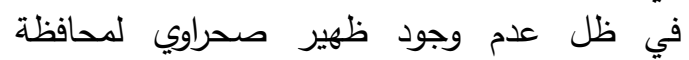

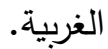




\title{
THE URBAN SPRAWL ON AGRICULTURAL LANDS IN GHARBIA GOVORNORATE
}

\author{
Kandil* M.A.A., El-Eraqi M.B. and Shehata M.S.
}

Agric. Economics Dept., Fac. of Agric., Ain Shams Univ., P.O. Box 68, Hadayek Shobra11241, Cairo, Egypt

${ }^{*}$ Corresponding author: mo.kandil1978@gmail.com

\section{ABSTRACT}

This study focuses on the evolution of urban encroachment on arable land in Egypt. There are three forms of encroachment on arable land. The first type is the removal of the fertile topsoil of agricultural land for the main purpose of bricks manufacturing. The second type is the setting aside of arable land and letting the land go unproductive for long time periods. The third type is the permanent conversion of arable land to buildings. The total acreage lost to encroachment from January 25, 2011 revolution till November 18, 2018 is about 85 thousands feddans of fertile land.

The first type of topsoil removal constitutes 7.7 percent of the total lost acreage. While setting aside of arable land constitutes 35.5 percent and the conversion of arable land to buildings constitutes 57.8 percent of total land lost to encroachment .

Rapid population growth is the main driver for accelerating encroachment on arable land in Egypt. This is especially evident in the governorates that are not endowed with desert backyard. Gharbeya governorate is a good example of densely populated regions with no desert backyard that could be used for urban expansion. The study
\end{abstract}

reveals that population in Gharbeya grew during the period 2006-2017 with an annually rate of 2.1 percent.

While cultivated area and cropped area declined with an annual rate of 1006 feddans and 2992 feddans respectively during the same time period.

The continued encroachment on agricultural land is a major threat to Egypt's food security due to the limited base of arable land in Egypt. In fact per capita share of arable land is declining very rapidly over the years. For example, the ratio of population to arable land increased from 10.4 in 2006 to 15.4 in 2017 . The country is attempting to make up for the lost land through reclamation of desert land. Unfortunately, reclamation of desert land is very expensive endeavor and requires major investment in basic infrastructure such as roads, irrigation networks, power grids, and social infrastructure. Therefore it is of utmost importance for the government to pay due attention to the problem of urban encroachment on old arable land and devise policies and legislations that would put a brake on this phenomena .

Keywords: Encroachment of Agricultural lands, Urban expansion in Gharbia Governorate

$$
\text { تحكيم: ا.د محمود صادق العضيمي } 1 \text { ألفت علي ملوك }
$$

